\title{
TRANSPORTE HIDROVIÁRIO, PORTOS E TERMINAIS INTERIORES NA AMAZÔNIA BRASILEIRA: uma análise sobre seus papéis na política pública territorial
}

\author{
WATERWAYS TRANSPORTATION, PORTS AND INLAND \\ TERMINALS AT BRAZILIAN AMAZON: an analysis of their roles \\ in public policy territorial
}

\begin{abstract}
Jondison Cardoso Rodrigues
Doutorando em Ciências - Desenvolvimento Socioambiental pelo Programas de Pós-Graduação em Desenvolvimento Sustentável do Trópico Úmido UFPA jondisoncardosorodrigues@yahoo.com.br

Jovenildo Cardoso Rodrigues Doutorando em Geografia pela Universidade Estadual Paulista Júlio de Mesquita Filho (UNESP), Docente substituto da Faculdade de Cartografia e Geografia UFPA jovengeo@yahoo.com.br

Edna Maria Ramos de Castro Docente dos Programas de Pós-Graduação em Desenvolvimento Sustentável do Trópico Úmido (PPGDSTU/NAEA/UFPA) e do Programa de Pós-Graduação em Ciências Ambientais UFPA edna.mrcastro@gmail.com
\end{abstract}

\begin{abstract}
RESUMO
O território brasileiro vem passando por um acelerado processo de reestruturação produtiva e reestruturação regional, como resultado de novas estratégias empresariais e governamentais no sentido de intensificar conexões e inseriras regiões brasileiras ao movimento do capitalismo global. Assim, os últimos anos do século XXI constituem momento marcado por uma série de políticas públicas territoriais pautadas em investimentos infraestruturais no Brasil. Uma das áreas de infraestrutura que teve grande canalização foi o setor hidroviário, proveniente de várias políticas, planos e programas, a saber:o Plano Nacional de Logística e Transporte (PNLT); a Iniciativa de Integração da Infraestrutura Regional Sul-Americana (IIRSA) e o Programa de Aceleração do Crescimento (PAC). O setor hidroviário foi um dos setores que mais foi injetado investimentos, particularmente no transporte hidroviário, nos portos e nos terminais interiores, sobretudo na Amazônia, buscando promover, além da integração física (inter)nacional e defesa do território amazônico, o aumento dos fluxos de mercadorias, a captura de capitais e a fluidez nas relações de trocas de maneira à obter divisas ao Estado-nação brasileiro. Com efeito, este artigo objetiva analisar o papel do transporte hidroviário, dos portos e dos terminais interiores na Amazônia brasileira, no
\end{abstract}


âmbito das "novas" estratégias de políticas territoriais e dos projetos de infraestrutura (PNLT, PAC, IIRSA), para o "desenvolvimento sustentável".

Palavras-chave: Amazônia, Infraestrutura, Transporte hidroviário, Terminais interiores e portos,Logística.

\begin{abstract}
The Brazilian territory has been undergoing a rapid process of productive structure and regional restructuring, as a result of new business strategies and government to intensify connections and insert Brazilian regions to the movement of global capitalism. So the last years of the XXI century were marked by a series of territorial public policies guided by infrastructure investments in Brazil. One of the areas of infrastructure that had been increased is waterway sector, from various policies, plans and programs, namely: The National Plan of Logistics and Transport (PNLT); the Integration Initiative of Regional Infrastructure South American (IIRSA) and Development Acceleration Program (PAC). The waterway sector have been one of the sectors that more invested, particularly in waterway transport, ports and interiors terminals, especially in Amazon, intended to promote, beyond the international physical integration and defense of the Amazon territory, the increase of the commodities flow, the capital capture and the flow on exchanges relations, to capture foreign currency to the Brazilian Nation State. So, the objective of this study is to analyze the role of the waterway transport, ports and terminals interiors at Brazilian Amazon, inside the "new" strategies of territorial policies and infrastructure projects (PNLT, PAC, IIRSA), for the "Sustainable Development".
\end{abstract}

Keywords: Amazon, Infrastructure, Territorial Public Policies, Waterway Transport, Terminals interiors and ports, Logistic.

\title{
Introdução
}

O Brasil dispõe de uma das maiores costas litorâneas do mundo, com mais de 7 mil km, e uma vasta rede de vias navegáveis, com mais de 27 mil km (GODOY, 2011; ANTAQ, 2011). Além disso, o país possui uma quantidade considerável de hidrovias interiores, a saber: a hidrovia do rio Madeira, do Tapajós, do Solimões-Amazonas, a hidrovia do Sul, a hidrovia do Paraguai, a Tocantins-Araguaia, Paraná-Tietê (KAISER; BEZERRA; CASTRO, 2013).

Essas dimensões territoriais navegáveis são elementos condicionantes de uma potencialidade natural para o transporte hidroviário brasileiro (VALOIS, MEDINA; BOTTER, 2012). No entanto,mesmo com a não utilização de todo seu potencial, ela contribuiu para que houvesse um aumento significativo na movimentação de cargas nos Geo UERJ. Rio de Janeiro - Ano 16, nº. 25, v. 1, $1^{\circ}$ semestre de 2014, pp.115-137 
portos brasileiros. Em 2012, essa movimentação atingiu um patamar de 903.765.474t, dos quais 74,16\% efetuaram-se por viagem de longo curso, 22,2\% em cabotagem e $3,3 \%$ por viagem interior, cujos portos públicos tiveram movimentação de 316.188.401t e terminais de uso privativo, 587.577.073t (ANTAQ, 2013a). O ano de 2012 teve um aumento percentual de $101,99 \%$, em relação a 2011 e mais de $249,78 \%$ comparado a 1994.

Tal crescimento, de maneira geral, relaciona-se com a lei de Modernização dos Portos (Lei 8.630/1993) que dispõe (ou dispunha) sobre o regime jurídico de exploração dos portos organizados, sobre as instalações portuárias e dá outras providências, no sentido de eliminar os obstáculos ao desenvolvimento do comércio exterior brasileiro e ampliara oferta de serviços, reduzindo os custos de movimentação de mercadorias (SÁ, 2008).

Essa lei introduziu dispositivos fundamentais: a) de transferência de parte das operações para a iniciativa privada, na figura do operador portuário, b) a criação do Conselho da Autoridade Portuária (CAP); e, c) o Órgão Gestor de Mão-de-Obra (OGMO). No caso do CAP caberia: deliberar, consultar e normatizar as atividades intraportuário com finalidade de desburocratização do setor. Já o OGMO ficava responsável de oferecer a força de trabalho e por arrecadar e repassar os valores de remuneração e encargos aos trabalhadores (SÁ, 2008; DIEGUEZ, 2007; MONIÉ, 2011).

A referida lei, na sua essência, objetivava, em curto prazo, a descentralização e desregulamentação do setor, a redução da atuação do Estado, o aumento da participação da iniciativa privada, a racionalização do uso da mão-de-obra e a maior capacitação do trabalhador; a médio prazo, buscava a melhoria da qualidade da mão-de-obra, a racionalização do ambiente de trabalho (estímulo à polivalência) e a redução dos preços e tarifas; finalmente, a longo prazo, o aumento da eficiência e competitividade dos portos (NASCIMENTO, 2005).

A respeito dessa lei, Monié (2011) enfatiza que ela esteve imersa na tendência de reestruturação do sistema marítimo-portuário que precisava atender a demandas de uma nova economia em vias de internacionalização, de integração das esferas da produção e do consumo, do transporte e de informações. 
A respectiva reestruturação constitui-se condição e resultado de uma "revolução" no transporte hidroviário e na sua modernização tecno-informacional portuária. Para tanto, algumas ações estratégicas foram fundamentais: a dragagem; maiores profundidades dos canais de acesso; informatização das atividades; guindastes elétricos; rebocadores; balanças; empilhadeiras; tratores; sugadores para trigo; a especialização das embarcações (granéis sólidos, líquidos e contêineres); o porte da embarcação e o sistema de propulsão (MOURA; BOTTER, 2011).

Todas essas estratégias representam práticas de gestão que, associadas a inovações tecnológicas implementadas, visam aumentar a movimentação de fluxos de mercadorias para atender demandas do comércio exterior. Vale ressaltar ainda que essa "revolução" foi e é necessária, já que o transporte marítimo brasileiro é responsável pelo escoamento de cerca de $50 \%$ de volumes financeiros e $99 \%$ da quantidade em peso das mercadorias (PEREIRA; SANTOS NETO; LESSA,2011).

Com efeito, levando em consideração os elementos apresentados, o artigo objetiva analisar o papel do transporte hidroviário, dos portos e terminais interiores na Amazônia brasileira, no âmbito das "novas" estratégias de políticas territoriais e dos projetos de infraestrutura (PNLT, PAC, IIRSA) para o "desenvolvimento sustentável". O fio condutor, isto é, a questão central do artigo é: Qual o papel e a(s) estratégia(s) dos investimentos no setor hidroviário (transporte hidroviário portos, terminais interiores- e as interações desses componentes logísticos), advindos de políticas públicas territoriais na Amazônia brasileira?

$\mathrm{O}$ artigo está organizado em quatro partes. Trata de forma sistemática e contextualizada na (nessa) introdução e nas considerações finais (criticamente). Os outros dois tópicos são divididos: nos investimentos no setor hidroviário (portos e terminais) no Brasil e na Amazônia, advindos, sobretudo, do PAC; e, de uma análise crítica sobre o papel e as estratégias dos investimentos no setor hidroviário na Amazônia. Além disso,neste último tópico, apresenta-se e analisa-se esses investimentos como elemento "geopolítico" mais profundo, que vão para além da busca (somente) da promoção da integração física (inter)nacional e defesa do território amazônico; por fim, “mostra(ndo)” os “impactos negativos” nas áreas adjacentes desses empreendimentos infraestruturais. 


\section{Investimentos no setor hidroviário: portos e terminais no Brasil e para Amazônia}

Segundo alguns documentos (de planejamento setorial e global em infraestrutura) institucionais brasileiros (BRASIL, 2008a; 2008b; BRASIL, 2010) até 2022 irão ocorrer uma série de investimentos no setor hidroviário como forma de diminuir o custo Brasil, consequentemente, objetiva-se, de maneira geral, a ampliação, modernização e operação eficiente de transportes, transporte marítimo de cabotagem e fluvial, hidrovias, eclusas, portos, aeroportos, energia, telecomunicações e serviços tecnológicos.

O objetivo de muitos planos, como o PNLT, o PAC e o IIRSA, é, sobretudo, ampliar a capacidade de fluxos de mercadorias nos portos e a criação de outros terminais e hidrovias (vide Mapa1 referente as obras do PAC), para reverter o tempo de espera para embarque e/ou desembarque e para liberar uma carga que, segundo Brito (2010), é, em média, de 4 a 5 dias, enquanto nos grandes portos do mundo, mais "eficientes", leva-se, em média, um dia; ponto esse de estrangulamento para ganhos de produtividade, competitividade e eficiência internacional brasileira (PADUA; SERRA, 2006), e, consequentemente, para se conseguir uma estocagem eficiente e capacidade de reposição, além da troca de informações e da utilização do Just-in-time. Em segundo plano, buscando-se reverter um aspecto característico do fluxo de mercadorias no Brasil, associado ao uso intensivo do modal rodoviário (MOURA; BOTTER, 2011), um dos transportes mais caros para movimentação de mercadorias. 
Figura 1: Mapa de "localização" dos investimentos do PAC em modais na Amazônia

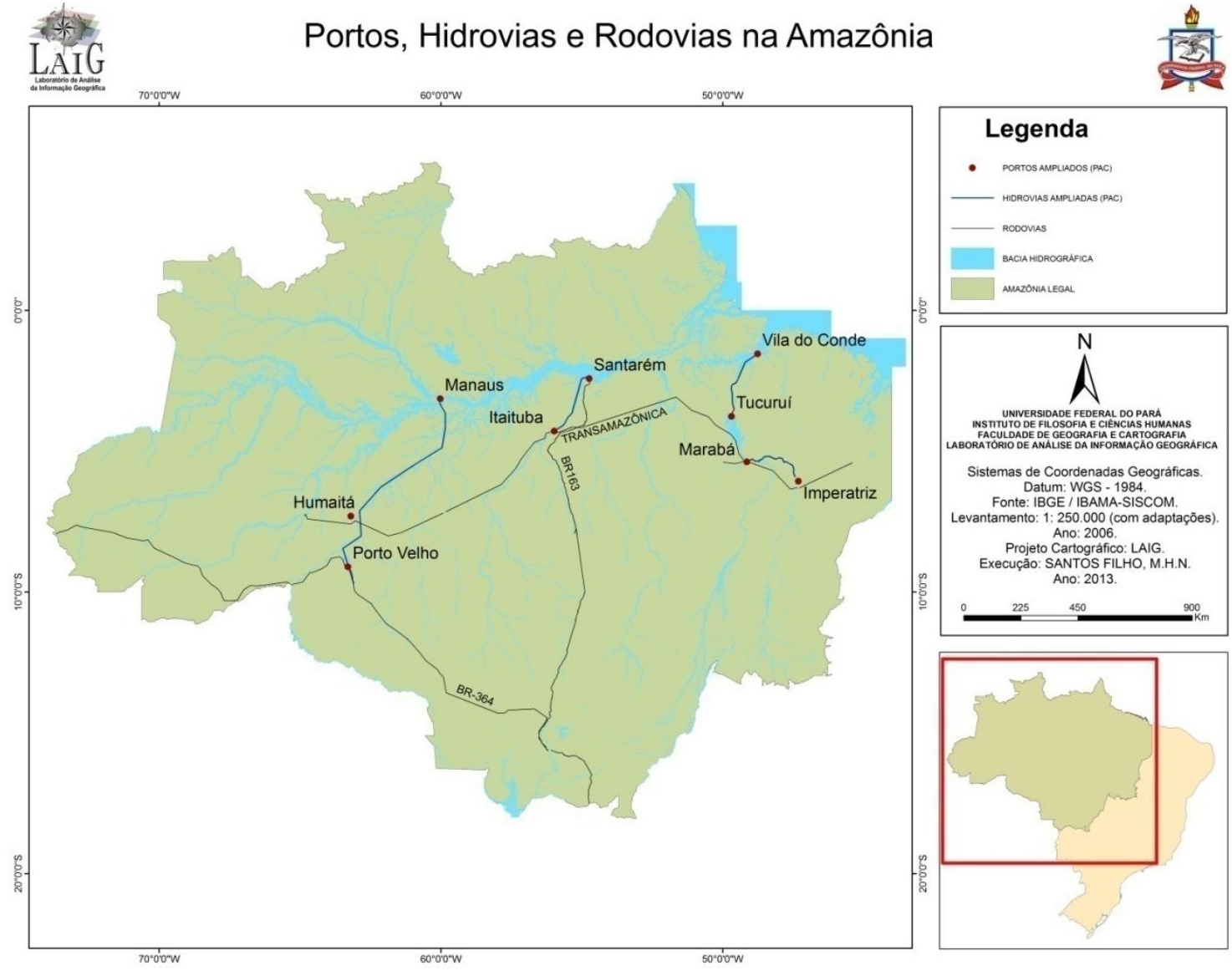

O mapa acima, elaborado a partir de informações disponibilizadas pelo Ministério do Planejamento, Orçamento e Gestão (MPOG) em Brasil (2013a), ilustra que há na Amazônia ações prioritárias do PAC, que são os portos, os terminais e as hidrovias. Entre os portos destacam-se o Porto de Porto Velho, de Santarém (juntamente com de Itaituba) e de Vila do Conde, cujas obras são: a construção do TMU2 (Terminal de Múltiplo Uso 2) e da rampa Roll-on-Roll-off (concluído) no Porto de Vila do Conde; a ampliação do Píer Principal do Porto de Vila do Conde (já concluído segundo Brasil (2013b)), a construção do TMU2 e a ampliação do TMU1 (Terminal de Múltiplo Uso 1) no Porto de Santarém e a expansão do Terminal Hidroviário de Porto Velho.

Além disso, dentro das ramificações dos rios da bacia amazônica (sobretudo, no Estado do Amazonas (AM), Pará (PA) e Rondônia (RO) (vide Mapa), há projetos de construção e manutenção de mais de 73 terminais hidroviários, sendo sete terminais concluídos no AM (São Raimundo, Tabatinga, São Sebastião do Uatumã, Nhamundá, 
Terminal Hidroviáro Urucurituba, Terminal Hidroviário Manaquiri e Terminal Hidroviário Humaitá); como também há 18 terminais em obras no AM e 3 terminais no PA; além de alguns terminais estarem em fase de ação preparatória: 9 terminais no AM, 11 no PA e 1 em RO (BRASIL, 2013a).

Por fim, no setor hidroviário (hidrovias) há dentro dos investimentos do PAC, a dragagem, o derrocamento e a sinalização da hidrovia do Rio Madeira, do Rio Amazonas, do Rio Tapajós e da hidrovia do Rio Tocantins (esta interligando Marabá a Imperatriz, vide Mapa).

O PAC 1 apresenta investimentos no setor hidroviário na Amazônia, distribuídos da seguinte forma (Tabela 1):

Tabela 1 - Investimentos de acordo com o setor hidroviário advindos do PAC 1 (em milhões de reais)

\begin{tabular}{ccccc}
\hline Setor & $\mathbf{2 0 0 7 - 2 0 1 0}$ & $\mathbf{2 0 1 1 - 2 0 1 4}$ & Pós 2014 & Total por obra \\
\hline Portos & 789,1 & 4,8 & 0,3 & 794,2 \\
Hidrovias & 1009,9 & 2,6 & 0,1 & 1012,6 \\
Marinha mercante & 17 & 36,7 & - & 53,7 \\
Total geral (milhões) & 1.816 & 44,1 & 0,4 & $1.808,5$ \\
\hline
\end{tabular}

Fonte: elaborado a partir de Brasil (2011a).

Obs.: Os investimentos, no período de 2007-2010, foram todos aplicados. Já os referentes a 2011-2014 e pós-2014 estão previstos.

Na região amazônica brasileira, os investimentos do PAC 1, no setor hidroviário, chegam a quase dois bilhões de reais, cujas obras priorizadas e concluídas foram: 1) as eclusas de Tucuruí (965,5 milhões - vide Mapa), que absorveu o maior percentual desse setor; 2) dez terminais - $\mathrm{R} \$ 44,4$ milhões; 3) os portos, com 14 empreendimentos - R\$ 789,1 milhões; e, 4) o financiamento de 301 embarcações e 5 estaleiros. E, ainda, dentro do PAC (que inclui o PAC 2) serão investidos na Amazônia (Tabela 2):

Tabela 2 - Investimentos de acordo com o setor hidroviário, advindos do PAC 2 (em milhões de reais)

\begin{tabular}{|c|c|c|c|c|c|c|}
\hline Estado & Setor & $\begin{array}{c}2011 \text { a } \\
2014 \\
\text { Exclusivo } \\
\end{array}$ & $\begin{array}{c}\text { Pós } 2014 \\
\text { Exclusivo } \\
\end{array}$ & $\begin{array}{c}2011 \text { a } \\
2014 \\
\text { Regional } \\
\end{array}$ & $\begin{array}{l}\text { Pós } 2014 \\
\text { Regional } \\
\end{array}$ & $\begin{array}{c}\text { Total por } \\
\text { obra Geral }\end{array}$ \\
\hline Pará & Portos & 148,4 & 48 & 355 & - & 551,4 \\
\hline Pará & $\begin{array}{l}\text { Hidrovias } \\
\text { Marinha }\end{array}$ & 23,99 & 67 & 11,72 & 11,72 & 114,43 \\
\hline Pará & mercante & 36,75 & - & - & - & 36,75 \\
\hline Amazonas & Portos & & - & 92 & - & 92 \\
\hline
\end{tabular}




\begin{tabular}{llccccc} 
Amazonas & Hidrovias & 317,89 & 119,51 & 144,17 & - & 581,57 \\
& Marinha & & & & & 135 \\
Amazonas & mercante & 123,5 & - & - & - & 2,4 \\
Acre & Hidrovias & 2,4 & - & - & - & 92 \\
Amapá & Portos & - & - & 92 & - & 190,27 \\
Rondônia & Hidrovias & 28,4 & 17,7 & 144,17 & - & \\
Total & & & & & & 11,72 \\
Geral & & 681,33 & 252,21 & 602,89 & $1.795,82$ \\
\hline
\end{tabular}

Fonte: elaborado a partir de Brasil (2013b).

Somados, os investimentos do PAC 1 e 2 no setor hidroviário são superiores a três bilhões de reais, dos quais os portos paraenses e amazônico são destinados o maior fluxo financeiro (cabe enfatizar que até 2014 serão 7,5 bilhões investidos nos portos brasileiros). Recurso esse que ainda aumentará, pois, a partir do dia 6 de dezembro 2012, como lançamento do Programa de Investimentos em Logística- Portos (complementar ao PAC), cujo objetivo do programa é incentivar a modernização da infraestrutura e da gestão portuária, busca-se: expandir os investimentos federais no setor portuário visando à redução de custos em planejamento; proporcionar o aumento da eficiência portuária e dos fluxos de mercadorias, sobretudo, ao mercado exterior. Com isso atrair investidores e empresas dispostas compartilhar ganhos sistêmicos (econômicos, sociais e simbólicos), vantagens competitivas (PÁDUA; SERRA, 2006), e garantir os fluxos internos, a dinamização da economia e o desenvolvimento regional (SILVEIRA; JULIO, 2013).

Dentro desse programa serão canalizados aproximadamente $\mathrm{R} \$ 54,2$ bilhões, destinados a estimular os arrendamentos de áreas dentro dos portos e a construção e ampliação de Terminais de Uso Privativo -TUPs, sendo R\$ 31 bilhões até 2014/2015 e R \$ 23,2 bilhões entre 2016/2017. Os portos beneficiados na Região Sudeste são os de Espírito Santo, Rio de Janeiro, Itaguaí e Santos; no Nordeste, Cabedelo, Itaqui, Pecém, Suape, Aratu e Porto Sul/Ilhéus; no Norte, Porto Velho, Santana, Manaus/Itacoatiara, Santarém, Vila do Conde e Belém/Miramar/Outeiro; e, no Sul, o Porto de Paranaguá/Antonina, São Francisco do Sul, Itajaí, Imbituba e Rio Grande (BRASIL, 2013c).

As tabelas acima expressam a ação do governo federal, por meio do PAC, que vem priorizando a manutenção, restauração e expansão do setor logístico portuário, para 
aumentar a eficiência logística dos portos brasileiros, a fim de que se possa imprimir ao setor maior competitividade e dinamismo, como forma de reduzir os custos de transporte aquaviário e contribuir para o desenvolvimento do país (BARROS; BARROS,2013). Esse objetivo do PAC ao setor logístico portuário está expresso também no PNLT (Plano Nacional de Logística e Transportes) e IIRSA (Iniciativa de Integração da Infraestrutura Regional Sul-Americana), pois segundo Castro (2012) assumem a mesma orientação de integração competitiva, adotando um modelo de modernização com base em megaprojetos de investimentos.

No caso do PNLT, o volume a ser injetado no setor aquaviário até 2023 é de 75,860 bilhões de reais, e somente na região amazônica os investimentos são acima do total. Serão injetados 12,081 trilhões (BRASIL, 2007). Cabe assinalar que o Plano Plurianual - PPA 2012-2015 destinará, ao setor hidroviário (para Amazônia, por via do PNLT), um total de R \$ 3.995.978.470, cujas obras prioritárias são:

> Implantação do Porto de Manaus Moderna/Amazonas (R \$ 105 milhões);

$>$ Adequação da navegabilidade da Hidrovia do Rio Madeira (R\$ 154.170.000);

$>$ Construção do Porto Fluvial Intermodal no Rio Tocantins em Marabá/Pará (R\$ 200 milhões);

> Construção da eclusa de Estreito no Rio Tocantins (R\$ 800 milhões) e implantação do Porto no Rio Madeira em Porto Velho/Rondônia (R\$ 300 milhões);

> Construção das eclusas no Complexo do Rio Madeira ( $\$ 700$ milhões);

$>$ Adequação da navegabilidade da Hidrovia Tocantins-Araguaia (R\$ 110 milhões);

$>$ Adequação de estruturas de acostagem e de operação de cargas no Porto de Vila do Conde/Pará (R\$ 1.526.808.470);

Adequação de estruturas de acostagem e de operação de cargas no Porto de Santana/Amapá (R\$ 100 milhões) (BRASIL, 2012).

O IIRSA possui a carteira de investimentos menores no setor hidroviário na região amazônica, correspondendo a apenas U\$ 211.220.000 (IIRSA, 2011), divididos da seguinte forma: Rede de Terminais Fluviais na Amazônia (200 milhões); melhoria da navegabilidade do Rio Içá nas redes de hidrovias do rio Amazonas (8 milhões); melhoria da navegabilidade do Sistema Solimões-Amazonas (1 milhão), Portos de 
Santarém e Itaituba (2,220 milhões). Considerando os elementos apresentados, qual o seria o papel do transporte hidroviário, portos e terminais interiores na Amazônia brasileira nas políticas públicas territoriais de infraestrutura? A seguir serão delineadas algumas reflexões a esse respeito.

\section{O transporte hidroviário, portos e terminais interiores na Amazônia brasileira: uma análise crítica}

Os investimentos em transporte hidroviário em vias interiores são motivados não por uma questão meramente geográfica natural, em que pese alguma relevância da localização geográfica, mas sim devido aos custos comparativos dos preços entre modais de transporte, pois o rodoviário é o segundo mais caro, só perdendo para modal aéreo.

A esse respeito, Lessa (2009) afirma que os modais de transporte apresentam a relação dólar/tonelada por cada quilômetro, da seguinte maneira (Tabela 3):

Tabela 3: Relação dólar/tonelada por cada quilômetro, por modalidade de transporte*

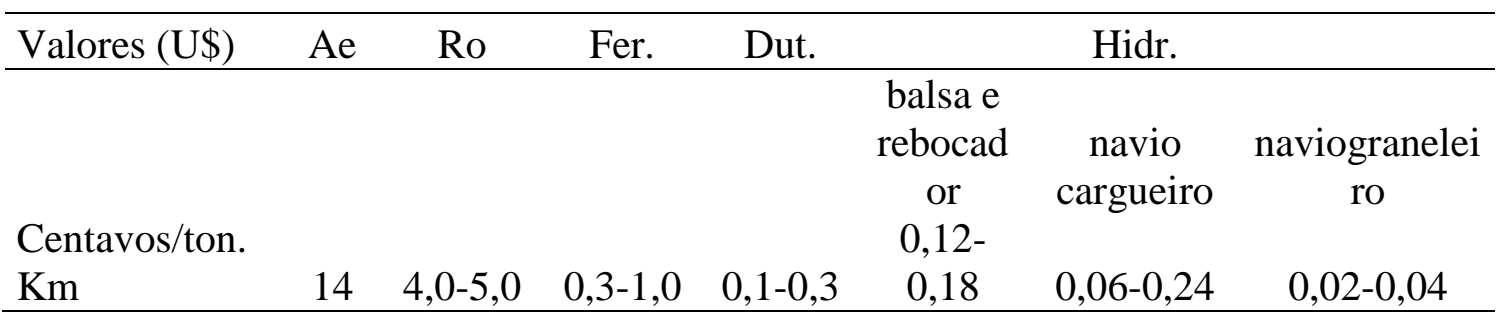

Fonte: elaborado a partir de Lessa (2009, p.79).

* Ae: Aéreo; Ro: Rodoviário Fer: Ferroviário Dut.: Dutoviário; Hidr.: Hidroviário

Com efeito, o modal hidroviário é o mais econômico no que concerne à infraestrutura: são 34 mil dólares para $1 \mathrm{~km}$ de infraestrutura, enquanto o ferroviário custa 1,4 milhões e o rodoviário 440 mil (SOARES, 2012).

Os investimentos em transporte hidroviário, terminais interiores e portos na Amazônia apresentam como motivação não apenas a integração física/espacial sulamericana, a defesa do território amazônico e o aumento na eficiência e nos fluxos de mercadorias entre países sul-americanos, como analisado na perspectiva generalista da discussão, desenvolvida nos trabalhos de Monteiro e Coelho (2004) e Monteiro, Coelho e Barbosa (2011). Busca-se, sobretudo, a expansão de dinâmicas estruturantes no território brasileiro, de maneira a se obter maior nível de fluidez de mercadorias, a 
captura de capitais e a fluidez nas relações de trocas de maneira à obtenção de divisas ao Estado-nação brasileiro (elevação de taxas de lucro), resultantes da exportação de comodietties para o mercado mundial.

Os projetos do PAC, PNLT e IIRSA buscam construir uma integração modal (ligações) que se seguem para todo o Brasil e o continente sul-americano. A título de exemplificação se tem as seguintes obras estruturantes (ligações, representadas por $\leftrightarrow$ ):

$\checkmark$ Ponte internacional sobre o rio Oiapoque $\leftrightarrow$ a Br-156 no Amapá $\leftrightarrow$ Porto do Amapá $\leftrightarrow$ mercado exterior (transporte marítimo);

Reabilitação da rodovia Caracas-Manaus $(\mathrm{Br}-432) \leftrightarrow$ porto de Manaus (ligandoaeroporto de Manaus) $\leftrightarrow$ terminais interiores $\leftrightarrow$ Mercado exterior (transporte marítimo);

Rodovia Bonfim $\leftrightarrow$ Lethem $\leftrightarrow$ Lindem - Geogetown $\leftrightarrow$ Boa Vista $\leftrightarrow$ Br-432 $\leftrightarrow$ Br$174 \leftrightarrow$ porto de Manaus $\leftrightarrow$ a rede de terminais $\leftrightarrow$ mercado exterior (transporte marítimo);

Hidroviária Teles Pires-Tapajós $\leftrightarrow$ Rodovia Cuiabá-Santarém (Br-163) $\leftrightarrow$ Porto de Santarém $\leftrightarrow$ mercado exterior (transporte marítimo);

Construção e pavimentação de 210 km entre Sena Madureira e Cruzeiro do Sul, Br$364 \leftrightarrow$ hidrovia do rio Madeira-terminais interiores $\leftrightarrow$ Porto de Manaus $\leftrightarrow$ Mercado exterior (transporte marítimo);

Porto de Vila do Conde $\leftrightarrow$ hidrovia Tocantins-araguaia (passando pelas eclusas de Tucuruí) $\leftrightarrow$ Br-230 (Transamazônica) $\leftrightarrow$ estrada de Ferro norte-sul (com integração com a ferrovia leste-oeste) $\leftrightarrow$ Marabá (ou Itaqui) $\leftrightarrow$ Mercado exterior (transporte marítimo);

$\checkmark$ Navegabilidade do sistema fluvial Solimões $\leftrightarrow$ Navegabilidade do Rio Içá $\leftrightarrow$ navegabilidade do rio madeira entre Porto Velho $\leftrightarrow$ Guyaramerim $\leftrightarrow$ terminais interiores - hidrovia do rio madeira $\leftrightarrow$ cidade de Porto velho $\leftrightarrow$ Cuiabá (via Br-364) $\leftrightarrow$ Porto de Santarém $\leftrightarrow$ Mercado exterior (transporte marítimo).

Essas integrações buscam primeiramente construir a multimodalidade e posteriormente a constituição de um sistema sincronizado dos modais (RODRIGUE, 1999) pela intermodalidade, já que o Brasil caracterizou-se historicamente pelo privilegiamento de um único modal de transporte, quando não, pelo compartilhamento 
entre sistema hidroviário e ferroviário, ou mesmo entre sistema rodoviário e ferroviário, cuja gênese encontra-se relacionada a estratégias políticas e econômicas concebidas e implementadas pelo governo brasileiro, principalmente a partir dos anos de 1970.

Acevedo-Marin (2004), Castro (2009, 2010), Monteiro e Coelho (2004) afirmam que para o caso da Amazônia, até os anos de 1960, o sistema hidroviário constituía-se como modal de transporte hegemônico, quando não compartilhado pelo sistema ferroviário, mas nunca integrado e sincronizado. Por sua vez, o período que compreende as três décadas posteriores aos anos de 1960 serão marcados por uma série de transformações nas lógicas de reorganização do espaço amazônico, com implementação e hegemonia do sistema rodoviário, e a diminuição significativa do uso do sistema de transporte hidroviário de cargas (ACEVEDO-MARIN, 2004; CASTRO, 2009, 2010).

O período atual configura-se tempo histórico-geográfico marcado por uma configuração geopolítica e econômica do Governo brasileiro no sentido de intensificar o movimento de exportação de commodieties para o mercado mundial, de maneira a obter divisas para o país. Dentro dessa perspectiva, a multmodalidade em sincronia constitui elemento fundamental no âmbito das "novas" estratégias governamentais visando à promoção do desenvolvimento econômico do país.

Para tanto, as estratégias de investimentos infraestruturais em transportes hidroviários, portos e terminais interiores do PAC, PNLT e IIRSA constitui elemento fundamental, visando a "integração produtiva" da Amazônia ao mercado internacional, não somente sul-americano na supplychain de commodieties primárias, ou seja, na rede logística de commodieties pela integração intermodal (CASTRO, 2012; RODRIGUE, 2012). Isso se expressa na expansão da fronteira agrícola e no avanço de agentes econômicos em direção à Amazônia Ocidental, ao Amazonas e Acre, e aos países vizinhos (Peru, Bolívia e Colômbia), ao norte da Venezuela, constituindo uma retomada de interesses de mercado sobre o território Amazônico que se aliam aos programas governamentais e à nova geopolítica de integração sul-americana (CASTRO, 2008).

Os portos se inserem enquanto "nós" dessa rede logística global, já que são multipolos internacionais de fluidez (materiais e informacionais) que se conectam a outros territórios, como células, interfaces com outros portos mundiais, sendo 
influenciados por mudanças na organização logística territorial e intra/interempresas dos países (BARROS; BARROS, 2013; GUERRERO; ABAD, 2013).

As mudanças realizadas estão relacionadas com o movimento de expansão e reestruturação do capitalismo global, cujas manifestações e contradições resultam na constituição e fortalecimento de um movimento hegemônico manifestado a partir do desenvolvimento de redes colaborativas, entre os armadores, operadores portuários, agências marítimas, autoridades portuárias, órgãos de gestão de mão-de-obra, instituições financeiras, agências regulatórias e estado-nações.

Assim, os portos são elementos de sincronização entre sítios portuários internacionais, portos hubs andspoks (concentração e dispersão), constituindo-se "nó górdio" na fluidez e no aumento da integração entre os elementos do sistema complexo de produção mundial de relações e redes informacionais/relacionais (RODRIGUE, 1999), consequentemente, de influência no controle na/da supplychain mundiais (ROBINSON, 2002).

Os investimentos em terminais na Amazônia constituem ações que visam avanços na área de logística global, no armazenamento temporário nos terminais (pautado no modelo Just-in-time) para barateamento de remessas. Tais ações possibilitam a maior circulação dos fluxos de mercadorias, além de uma sincronização suave entre modos de transporte, transportadores e serviços de logística, por consequência, a sincronização entre operações marítimas e de transporte terrestre (RODRIGUE; NOTTEBOOM, 2009).

A respectiva estratégica encontra-se evidenciada no Plano Nacional de Integração Hidroviária (PNIH), lançado em 19 de fevereiro de 2013, "concebido" pela ANTAQ (Agência Nacional de Transportes Aquaviários), visando dois objetivos centrais, quais sejam: um estudo detalhado sobre as hidrovias brasileiras e a indicação de áreas propícias para instalações portuárias (ANTAQ, 2013d).

Além disso, o plano em questão objetiva analisar diferentes cenários logísticos, buscando avaliar a criação de terminais hidroviários e alternativas de escoamento, utilizando as hidrovias nacionais. Em suma, o PNIH apresenta como conclusão do relatório técnico e executivo, a potencialidade de utilização do modal hidroviário para seis bacias hidrográficas (do São Francisco, Sul, Tocantins, Amazônica, Paraguai, 
Paraná-Tietê), terminais e vias navegáveis, para o transporte de cargas, e a projeção da movimentação de cargas até o ano de 2030.

Dessa maneira, o planejamento estratégico, concebido e implementado pelo governo brasileiro, objetiva estabelecer novas ligações e pontos de mediação para intensificação de trocas comerciais, buscando atender as crescentes demandas, principalmente do mercado chinês, que somente em 2010 foi responsável por 36,15\% do volume de exportações da balança comercial brasileira e que absorveu/consumiu $66 \%$ de toda a soja brasileira (ANTAQ, 2011b).

A China configura-se como principal parceira comercial do Brasil, importando soja, minério de ferro, milho, fertilizantes e adubos, produtos químicos orgânicos e óleos minerais/oleaginosas da Amazônia (MDIC, 2013; FEARNSIDE; FIGUEIREDO; BONJOUR, 2013). Não obstante, alguns gargalos tendem a contribuir para a redução dos níveis de competitividade e de lucratividade dos produtos exportados pelo Brasil, a saber: os custos logísticos em combustíveis, fretes e seguro. Tais elementos implicam no aumento do preço do produto no mercado.

Diante disso, os investimentos em infraestrutura logística, no âmbito do transporte hidroviário, possibilitarão o desenvolvimento de um corredor de transporte multimodal, que envolverá as redes rodoviárias, hidroviárias, contribuindo substancialmente para a diminuição do preço final das mercadorias exportadas (JULIO; SILVEIRA, 2011), ao mesmo tempo capturando fluxos de capitais e a inscrição de determinados territórios ao mundo globalizado (MONIÉ, 2003).

Desse modo, os investimentos em transporte hidroviário buscam a integração e a sincronização modal na Amazônia, sobretudo, potencializando a produção e extração de mercadorias e seu escoamento para os principais mercados internacionais, principalmente porque as commodities primárias são direcionadas ao mercado exterior (a exportação), e no cenário de mercado global altamente competitivo é obrigatório que as empresas produtoras (via poder público, com investimentos em infraestrutura) realizem investimentos constantes em toda cadeia logística, para reduzir custos e, consequentemente, aumentara rentabilidade dos negócios e a competitividade global (BNDES, 1996). Competitividade essa principalmente com relação à soja norteamericana e argentina (FRIEND; LIMA, 2011). 
Essas políticas públicas territoriais de investimento em infraestrutura, ao buscar fortalecer vinculação com o mercado global, como forma de obter superávit primário pelas exportações, promovem a abertura e incorporação de novas fronteiras de recursos ao movimento de reprodução extensiva do capital, por meio da incorporação de terras (fronteira agrícola de grãos, milho e soja), bem como da exploração de madeira e da pecuária extensiva, insumos agrícolas, minerais energéticos, minerais metálicos, gemas (CASTRO, 2012; BRASIL, 2011b) e a produção de minero-metalúrgicos/siderúrgicos em proveito da iniciativa privada, resultando na inserção e reestruturação do território brasileiro e amazônico aos processos globais de reorganização capitalista (LEITÃO, 2009).

É dentro dessa perspectiva que se promove o ordenamento territorial e a produção de novas territorialidades em rede (CASTRO, 2007), caracterizadas pelo processo de redefinições políticas, jurídicas e econômicas, já que, segundo Castro (2012), os Estados nacionais transformaram-se em componente/jogador desse jogo econômico do mercado, enquanto ente"regulador"de políticas econômicas que tende a "sucumbir" à lógica liberalizante do capital e a certos acordos de agências reguladores internacionais.

Considerando a escala do território amazônico, essas políticas públicas territoriais de "desenvolvimento sustentável", no que tange aos investimentos em transporte hidroviário, portos e terminais interiores terão os seguintes impactos nas áreas adjacentes a esses empreendimentos infraestruturais: mudança brusca na paisagem com a construção de terminais; mudanças nas relações da população com o rio, já que a intensificação do fluxo de mercadorias através de grandes balsas e navios graneleiros poderá interferir na mobilidade das populações ribeirinhas que se deslocam via pequenas embarcações, em direção a centros urbanos maiores em busca de serviços, uma vez que, a maior fluidez de transportes de cargas em grandes balsas tende a aumentar a fiscalização da capitania dos portos e da ANTAQ.

Dentre os impactos sistêmicos decorrentes da implantação do corredor multimodal, que, para o caso da Amazônia brasileira, configurar-se-á pela predominância do transporte hidroviário, convém ressaltar o aspecto relacionado à poluição do ar causada pela eliminação de combustíveis fósseis de navios, além de 
vazamentos de combustíveis dessas embarcações, fato que pode interferir substancialmente na reprodução da ictiofauna da região e na reprodução social das populações ribeirinhas que vivem da atividade (trabalho) da pesca.

Outro impacto sistêmico é o incentivo a agricultura (patronal) de grãos de grande escala (monocultura), como a soja e milho, que provocará a abertura de novas áreas agricultáveis e a incorporação de terra por grandes e médios agentes econômicos nos entroncamentos modais. Isso poderá promover transformações de algumas áreas ditas carentes em regiões produtoras, sobretudo de grãos (ALMEIDA, 2011), ao mesmo tempo em que desorganizará as atividades produtivas locais contribuindo para o "aniquilamento" de modos de vida de populações que vivem e se reproduzem a partir de usos do rio e da terra. Além disso, conflitos territoriais entre garimpeiros, latifundiários, indígenas e populações tradicionais; além da violação de direitos sociais e étnicos, como o resultado da "desterritorialização" que atinge grupos de população tradicional, na extensão pan-amazônica (CASTRO, 2012; ALMEIDA; ACEVEDO-MARIN, 2010).

Com efeito, convém pensar criticamente a respeito desses projetos que vem sendo concebidos e implementados pelo poder público para a Amazônia brasileira, uma vez que, as experiências de modernização empreendidas por estratégias de políticas públicas territoriais geraram historicamente um passivo social de graves implicações (impactos negativos), principalmente a partir dos nos anos de 1970 e 1980, para a região amazônica, a saber: conflitos territoriais entre garimpeiros;concentração fundiária, com estabelecimento de grandes latifundiários; etnocídios de populações indígenas;segregação socioespacial e urbanização "caótica", como resultado de ações relacionadas a grandes projetos que visavam à inserção da Amazônia no contexto de dinâmicas capitalistas globais.

\section{Considerações Finais}

O território brasileiro e amazônico, no início do século XXI, vem passando por uma série de múltiplas e complexas transformações como resultado da relação entre processos de reestruturação produtiva e estratégias de planejamento e gestão governamental, que tendem a contribuir substancialmente para a redefinição das lógicas 
capitalistas de produção, distribuição e consumo, como possibilidade para ampliação de taxas médias de lucro do capital.

Para tanto, o poder público atual vem exercendo papel significativo no sentido de promover níveis de competitividade da produção, distribuição e consumo na economia brasileira, por intermédio de políticas públicas territoriais pautadas em matrizes de planejamento estratégico intersetorial e investimentos, de longo prazo em infraestrutura de transportes, energia e tecnologia, por meio do PAC, PNLT e IIRSA.

Tais planos e programas, concebidos e implantados pela instância governamental, tanto para o território brasileiro, quanto para a Amazônia brasileira, enquanto parte do processo de reestruturação do sistema portuário, visam incrementar fortes investimentos em infraestrutura no setor hidroviário, portos e terminais interiores, de maneira geral, paraelevar os níveis de competitividade da economia brasileira em relação ao mercado internacional.

Sob o manto de um discurso de "sustentabilidade socioambiental", os investimentos públicos na estruturação de um modal integrado e sincronizado, buscam estabelecer ligações via redes materiais e informacionais do território brasileiro e amazônico com os mercados globais, por meio de expansão de novas cadeias produtivas, hodings e clusters, de maneira a promover "ajustes espaciais" necessários à expansão do capital produtivo no território e ampliação da lucratividade do capital.

Dentro dessa perspectiva, as políticas públicas territoriais, pautadas por investimentos em infraestrutura, objetivam aumentar o superávit primário das exportações brasileiras, por intermédio de uma série de incentivos fiscais, tributário, financeiros e em infraestrutura, a abertura de novas fronteiras de recursos e incorporação de terras por grandes agentes econômicos como a Cargill, Bunge, Vale, Hermasa/Amagi, madeireiros e grandes pecuaristas de gado de corte. Além disso, contribuindo na abertura de nova(s) fronteira(s) agrícola(s) de grãos (milho e soja), exploração e exportação de madeira e pecuária extensiva, insumos agrícolas, minerais energéticos, minerais metálicos, gemas, produção e exportação de minerometalúrgicos/siderúrgicos, em benefício da iniciativa privada, o ordenamento territorial e produção de novas territorialidades em rede. 
Elemento emblemático do papel exercido pelo poder público na reestruturação logística da atividade portuária diz respeito aos novos investimentos em instalações portuárias (áreas propícias de investimentos) na bacia Amazônica, a saber (nos Estados): em Jacareacanga (Pará), Colares (Pará), Baião (Pará), Boa Vista (Roraima), Rorainópolis (Roraima), Cucuí (Amazonas), Peixe (Tocantins), Aguiarnópolis (Tocantins), Barra do Ouro (Tocantins), Itaúba (Tocantins), Miracema do Tocantins (Tocantins) (ANTAQ, 2013d).

Com efeito, as políticas públicas territoriais concebidas e implantadas pelo governo "atual", pautadas em matrizes de crescimento econômico por meio de estímulo à reestruturação do transporte hidroviário, de portos e terminais interiores, para além da produção de processos de integração física (inter)nacional e de defesa do território brasileiro, apresentam forte comprometimento com estratégias macroeconômicas de elevação de níveis de competitividade, relacionadas ao desenvolvimento econômico do país; marginalizando as contradições e implicações (impactos) negativas desses processos na escala local, a saber, as territorialidades conflituosas e violação de direitos étnicos e humanos que se estabelecem como resultado do paradoxo relacionado ao desenvolvimento desigual e combinado nos espaços capitalistas periféricos.

\section{Referências}

ACEVEDO-MARIN, Rosa Elizabeth. Civilização do rio, civilização da estrada: transportes na ocupação da Amazônia no século XIX e XX. Papers do NAEA (UFPA), n.170, p.1-24, 2004.

ALMEIDA, Guilherme. As Hidrovias como fator de desenvolvimento brasileiro. In: $\mathbf{2}^{\circ}$ Fórum Sobre Hidrovia - As hidrovias como fator de desenvolvimento brasileiro. Brasília: ANTAQ, 2011. Disponível em: <http://www.antaq.gov.br/portal/pdf/Palestras/ForumSobreHidroviaAgo11/Guilherme_ Almeida_Codevasf_e_hidrovias2.pdf>. Acesso em: 20 fev. 2013.

ALMEIDA, Alfredo Wagner Berno de; ACEVEDO-MARIN, Rosa Elizabeth. Campanhas de desterritorialização na Amazônia: o agronegócio e a reestruturação do mercado de terras. In: BOLLE, Willi; CASTRO, Edna; VEJMELKA, Marcel. (Org.). Amazônia: região universal e teatro do mundo. São Paulo: Globo, 2010. p.141-160.

ANTAQ - AGÊNCIA NACIONAL DE TRANSPORTES AQUAVIÁRIOS. Estatísticas da Navegação Interior 2010. Brasília: ANTAQ, 2011. 
Anuário Estatístico Aquaviário 2012. Disponível em: <http://www.antaq.gov.br/Portal/Anuarios/Anuario2012/21.htm>. Acesso em: 18 mar. 2013a.

.Anuário Estatístico Aquaviário 2011. Disponível em: <http://www.antaq.gov.br/Portal/Anuarios/Anuario2011/body/21.htm>. Acesso em: 17 mar. $2013 b$

Panorama Aquaviário, v.2, 2008. Disponível em: <http://www.antaq.gov.br/Portal/pdf/PanoramaAquaviario2.pdf>. Acesso em: 17 mar. $2013 c$.

PNIH - Plano Nacional de Integração Hidroviária. Bacia Amazônica. Relatório Executivo. Brasília: ANTAQ, 2013d. Disponível em: <http://www.antaq.gov.br/Portal/PNIH.asp>. Acessoem: 22 mar. 2013d.

BARROS, Cristiane Ferreira da Silva; BARROS, Cleyton Miranda.Suitability of brazilian ports to international standards of port needs: a case study in the port of Salvador. Journalof TransportLiterature, v.7, n.4, p.23-49, 2013.

BNDES - Banco Nacional de Desenvolvimento Econômico e Social. O Sistema Portuário Brasileiro. Informe Infra-Estrutura, n.2, p.1-7, 1996.

BRASIL. Plano Nacional de Logística e Transportes. Brasília: Ministério dos Transportes/Ministério da Defesa, 2007.

Ministério do Planejamento, Orçamento e Gestão. Secretaria de Planejamento e Investimentos Estratégicos. Estudo da Dimensão Territorial para o Planejamento: Volume II - Visão Estratégica Nacional. Brasília: MP, 2008a. 185 p.

Ministério do Planejamento, Orçamento e Gestão. Secretaria de Planejamento e Investimentos Estratégicos. Estudo da Dimensão Territorial para o Planejamento: Volume IV - Estudos Prospectivos - Escolhas Estratégicas. Brasília: MP, 2008b. 288 p.

Presidência da República. Secretaria de Assuntos Estratégicos. Brasil 2022: Trabalhos Preparatórios. Brasília: Presidência da República, SAE, 2010. 408 p.

Disponível

Programa de Aceleração do Crescimento- Relatórios por Estado. <http://www.pac.gov.br/pub/up/relatorio/92977484f42df916be3feadde1a42fa2.pdf>. Acesso: 17 jun. 2011a.

Secretaria de Assuntos Estratégicos. Atlas digital - Amazônia visão estratégica.Disponível em: < http://www.sae.gov.br/atlas/>. Acesso em: 18 jun. 2011 b.

Lei $n^{\circ}$ 12.593, de 18 de Janeiro de 2012. Institui o Plano Plurianual da União para o período de 2012 a 2015. Brasília, 2012.

Geo UERJ. Rio de Janeiro - Ano 16, nº. 25, v. 1, $1^{\circ}$ semestre de 2014, pp.115-137

ISSN: 1415-7543 E-ISSN: 1981-9021

http://www.e-publicacoes.uerj.br/index.php/geouerj 
2010.

Programa de Aceleração do Crescimento - $10^{\circ}$ Balanço - Janeiro a Abril de

<http://www.pac.gov.br/pub/up/relatorio/d473dfcab55fe26e4d3fb91f3df17ccc.pdf>.

Acesso em: 14 fev. 2013a.

PAC 2 - $5^{\circ}$ Balanço maio-set.2012. Disponível em: <http://www.pac.gov.br/pub/up/relatorio/c6c606b5b1d4b71831c69dead4909f25.pdf>. Acesso em: 23 mar. 2013b.

- Lançado programa de investimentos em portos. Disponível em: <http://www.pac.gov.br/noticia/83b7d344>. Acesso em: 19 Mar. 2013c.

BRITO, Pedro. Ciclo de palestras: Portos. Brasília: Presidência da República, Secretaria de Assuntos Estratégicos, 2010. 40 p.

CASTRO, Edna Maria Ramos de. Fronteira e territorialidades: atores locais e conexões transnacionais. In: FELDMAN, Sarah; FERNANDES, Ana (Org.). O urbano e o regional no Brasil contemporâneo: mutações, tensões, desafios. Bahia: EDUFBA, 2007.p.251-268.

A Amazônia e seu lugar central na integração sul-americana. In: NASCIMENTO, Durbens Martins (Org.). Relações internacionais e defesa na Amazônia. Belém: NAEA/UFPA, 2008. p.21-45.

Urbanização, pluralidade e singularidades das cidades amazônicas. In: CASTRO, Edna Maria Ramos de(Org.). Cidades na floresta. São Paulo: Annablume, 2009. p.13-39.

- Políticas de Estado e atores sociais na Amazônia contemporânea. In: BOLE,Willi; CASTRO, Edna; VEJMELKA, Marcel (Org.). Amazônia- região universal e teatro do mundo. São Paulo: Globo, 2010. p.105-122.

Expansão da fronteira, megaprojetos de infraestrutura e integração sulamericana. Caderno CRH, v.25, n.64, p.45-62, 2012.

DIÉGUEZ, Carla Regina Mota Alonso. De OGMO (Operários Gestores de Mão-deObra) para OGMO (Órgão Gestor de Mão-de-Obra): modernização e cultura do trabalho no Porto de Santos. 152f. Dissertação (Mestrado em Sociologia)- Programa de Pós-Graduação em Sociologia, Universidade de São Paulo, São Paulo, 2007.

FEARNSIDE, Philip M.; FIGUEIREDO, Adriano M. R.; BONJOUR, Sandra C. M. Amazonian forest loss and the long reach of China's influence. Environment, Development and Sustainability, v.15, n.2, p.325-338, 2013. 
FRIEND, J. Daniel; LIMA, Renato da Silva.Impact of transportation policies on competitiveness of Brazilian and U.S. soybeans: from field to port. Transportation Research Record: Journal of the Transportation Research Board, n.2238, p.61-67, 2011.

GODOY, Paulo Roberto Coelho de. O estado da arte das hidrovias brasileiras. In: $\mathbf{2}^{\mathbf{0}}$ Fórum Sobre Hidrovia - As hidrovias como fator de desenvolvimento brasileiro. Brasília, 2011. Disponível em: <http://www.antaq.gov.br/portal/pdf/Palestras/ForumSobreHidroviaAgo11/Paulo_Robe rto_Palestra_Congresso_24ago11.pdf>. Acessoem:28fev. 2013.

GUERRERO, Pablo; ABAD, Julieta.Port-centric development: strategic logistics investments. Nova York: Inter-American Development Bank, 2013. Disponível em: <http://idbdocs.iadb.org/wsdocs/getdocument.aspx?docnum=37580753>. Acesso em: 31 mar. 2013.

IIRSA. Proyectos de Brasil. Disponível em: <http://www.iirsa.org/ProyectosPais.asp?CodIdioma=ESP\&Pais=3>. Acesso em: 20 jun. 2011.

JULIO, Alessandra dos Santos; SILVEIRA, Márcio Rogério. Política macroeconômica e o papel do transporte na dinâmica econômica nacional. RevistaGeográfica de América Central, v.2, .n.47, p.1-17, 2011.

KAISER, IlzaMachado; BEZERRA, BarbaraStolte; CASTRO, LeslieIvanaSerino.Is the environmental policies procedures a barrier to development of inland navigation and port management? A case of study in Brazil.Transportation Research Part A: Policy and Practice, v.47, p.78-86. 2013.

LEITÃO, Karina Oliveira. A dimensão territorial do Programa de Aceleração do Crescimento: um estudo a partir do PAC no Estado do Pará e o lugar que ele reserva a Amazônia no desenvolvimento do país. 285f. Tese (Doutorado em Arquitetura e Urbanismo)-Programa de Pós-Graduação em Arquitetura e Urbanismo, Universidade de São Paulo, São Paulo, 2009.

LESSA, Carlos. Infraestrutura e logística no Brasil. In: CARDOSO JR, José Celso (Org.). Desafios ao desenvolvimento brasileiro: contribuições do conselho de orientação do IPEA. Brasília: IPEA, 2009. v.1 p.77-100.

MDIC - Ministério do Desenvolvimento, Indústria e Comércio Exterior. Balança Comercial Brasileira - Dados Consolidados - Jan-jun. 2012. Brasília: MDIC, 2012. Disponível em: <http://www.desenvolvimento.gov.br/arquivos/dwnl_1349207864.pdf>.Acesso em: 20 mar. 2013. 
MONIÉ, Frédéric. Planejamento territorial, modernização portuária e logística: o impasse das políticas públicas no Brasil e no Rio de Janeiro. In: MONIÉ, Frédéric; SILVA, Gerardo (Org.). A mobilização produtiva dos territórios. Rio de Janeiro: DP\&A, 2003, v. 1, p. 57-80.

Globalização, modernização do sistema portuário e relações cidade-porto no Brasil. In: SILVEIRA, Marcio Rogério (Org.). Circulação, Transportes e Logística: diferentes perspectivas. São Paulo: Outras Expressões, 2011. p. 299-330.

MONTEIRO,Maurílio de Abreu; COELHO, Maria Célia Nunes. As políticas federais e reconfigurações espaciais na Amazônia. Novos Cadernos NAEA, v.7, n.1, p. 91-122, 2004.

MONTEIRO,Maurílio de Abreu; COELHO, Maria Célia Nunes; BARBOSA,Estêvão José da Silva.Fronteira, corredores de exportação e rede urbana na Amazônia oriental brasileira. GEOgraphia, v.13, n.26, p. 37-65, 2011.

MOURA, Delmo Alves; BOTTER, Rui Carlos. O transporte por cabotagem no Brasil potencialidade para a intermodalidade visando à melhoria do fluxo logístico. Revista Produção Online, v.11, n.2, p.595-617, 2011.

NASCIMENTO, Jonas Pereira do. Vantagens e limitações decorrentes da implantação da lei de modernização dos portos. 117f. Dissertação (Mestrado em Ciências em Engenharia de Transportes)- Programa de Pós-Graduação de Engenharia, Universidade Federal do Rio de Janeiro, 2005.

PADUA, Claudio de Alencar; SERRA, Eduardo Gonçalves. Superação dos gargalos logísticos do setor portuário. Revista do BNDES, v.13, n.26, p.55-88, 2006.

PEREIRA, Luiz Andrei Gonçalves; SANTOS NETO, Narciso Ferreira dos; LESSA, Simone Lessa Narciso. As exportações do setor agroindustrial na região norte de Minas Gerais: logística e transportes.Revista de Geografia (UFPE), v.28, n.3, 2011.

ROBINSON, Ross. Ports as elements in value-driven chain systems: the new paradigm. Maritime Policy \& Management, v.29, n.3, p.241-255, 2002.

RODRIGUE, Jean-Paul.Globalization and the synchronization of transport terminals.Journal of Transport Geography, v.7, n.4, p.255-261, 1999.

RODRIGUE, Jean-Paul.The benefits of logistics investments: opportunities for Latin America and the Caribbean. Nova York: Inter-American Development Bank, 2012. Disponívelem: $<\mathrm{http}: / /$ www.iadb.org/en/publications/publicationdetail,7101.html $2 \mathrm{id}=40686 \% 20 \&$ dcLanguage=en $\&$ dcType=All $>$. Acessoem: 31 mar. 2013. 
RODRIGUE, Jean-Paul; NOTTEBOOM, Theo. The terminalization of supply chains: reassessing the role of terminals in port/hinterland logistical relationships. MaritimePolicy\& Management, v.36, n.2, 165-183, 2009.

SÁ, Maria Evelina Menezes de. Análise comparativa entre os portos de Recife e Suape: desafios para a Gestão ambiental.110f. Dissertação (Mestrado em Desenvolvimento e Meio Ambiente)- Programa de Pós-Graduação em Desenvolvimento e Meio Ambiente, Universidade Federal de Pernambuco, Recife, 2008.

SILVEIRA, Marcio Rogério; JULIO, Alessandra dos Santos. Os investimentos em transportes do Programa de Aceleração do Crescimento (PAC) e o efeito multiplicador brasileiro a partir do Governo Lula da Silva. Revista de Literatura dos Transportes, v.7, n.4, p.199-224, 2013.

SOARES, Marcos Machado. A evolução das hidrovias brasileiras visão da CNT. In: $\mathbf{2}^{\mathbf{0}}$ Fórum Sobre Hidrovia - As hidrovias como fator de desenvolvimento brasileiro. Brasília: ANTAQ 2011. Disponível em: <http://www.antaq.gov.br/portal/pdf/Palestras/ForumSobreHidroviaAgo11/Marcos_Soa res_2_Forum_Sobre_Hidrovias_apresentacao_Marcos.pdf >. Acessoem: 18jan. 2013.

VALOIS, Nayara A.L. de; MEDINA, AfonsoCelso; BOTTER, Rui Carlos.Potential of short sea shipping in Brazil. In: RIZZUTO, Enrico; SOARES, Carlos Guedes (Orgs.). Sustainable maritime transportation and exploitation of sea resources. London: Taylor \& Francis Group, 2012. p.801-806.

Artigo recebido para publicação em jan/14

Artigo aceito para publicação em abril/14 